\title{
Castaing microprobe analysis of doped polyacetylene films
}

\author{
M. Rolland, M. Aldissi, M. Cadene, J. F. Bresse and C. Benoit \\ Groupe de Dynamique des Phases Condensées (*), Laboratoire de Chimie Macromoléculaire, Laboratoire de \\ Microscopie Electronique et Microanalyse, Université des Sciences et Techniques du Languedoc, place E. Bataillon, \\ 34060 Montpellier Cedex, France
}

(Reçu le 18 août 1981, révisé le 18 février 1982, accepté le 22 février 1982)

\begin{abstract}
Résumé. - Le dopage a permis de modifier considérablement les propriétés électriques du polyacétylène, et a été le point de départ de l'intérêt considérable porté à ce matériau depuis quelques années. Ce court article met en évidence l'existence d'un dopage inhomogène observé avec les dopants $\mathrm{I}_{2}$ et $\mathrm{SbF}_{5}$. Il montre en conséquence les risques d'erreur que ces inhomogénéités peuvent introduire lors de l'interprétation de certaines mesures physiques.
\end{abstract}

\begin{abstract}
By doping, the electrical behaviour of polyacetylene film was considerably modified leading to the large development of the research in the field of conducting polymers. The aim of this paper is to point out the inhomogeneity of the dopant through the film cross section, in particular with $\mathrm{I}_{2}$ and $\mathrm{SbF}_{5}$. It is also evidenced that errors may be induced by these inhomogeneities in the interpretation of physical measurements.
\end{abstract}

1. Introduction. - Polyacetylene is a simple conjugated polymer, the interest of which was considerably increased by its remarkable properties produced by doping : for example, the electrical conductivity is enhanced by more than twelve orders of magnitude [1] and the doping process induces a semiconductor to metal transition [2] when the dopant concentration reach $y=0.01$ in the formula [CHA $]_{x}$. However, until now very sparse work about the dopant diffusion inside the film was published, only Bénière [3] pointed out the existence of inhomogeneous dopant concentration through the sample using the iodine radioactive method.

The aim of this work is to study and compare the various macroscopic diffusion coefficients of dopants inside the $(\mathrm{CH})_{x}$ films.

2. Experimental techniques and results. - Polyacetylene films $(100-300 \mu \mathrm{m}$ thick) were prepared using the technique developed by Ito et al. [4]. We always polymerize the monomer at $-78^{\circ} \mathrm{C}$ in order to favour the cis isomer, however we must notice that the product studied is always the trans isomer, because it is well known that the dopage induces the isomerization process [5]. The films were p-type doped with iodine or $\mathrm{SbF}_{5}$ vapour in equilibrium with their

(*) L.A. 233. liquid phase at $20^{\circ} \mathrm{C}$. Then they are plunged in an epoxy resin in such a way that it facilitates the examination of their cross section after polishing. Dopant elements (I, Sb) X-Rays emission profiles have been obtained by using a CAMECA microprobe MS 46 type with an accelerating voltage of $15 \mathrm{keV}$ and an electron probe current of $70 \mathrm{nA}$. In order to verify that a degradation of the sample doesn't take place, we also used an energy dispersive spectrometry system (LINK 860), joined with a JEOL scanning electron microscope (JSMU3-SDS) with a very low beam current (less than $1 \mathrm{nA}$ ). The results obtained with both these systems are identical. In all cases the electron beam diameter was $1 \mu \mathrm{m}$ and the ionization sphere diameter about $5 \mu \mathrm{m}$.

For the elements $\mathrm{I}$ and $\mathrm{Sb}\left(\mathrm{I}_{2}\right.$ or $\mathrm{SbF}_{5}$ doping), the corresponding counting rate of $\mathrm{X}$-ray intensity was compared with the standard's one, and even with an inhomogeneous sample as $(\mathrm{CH})_{x}$, we can assume a correct ratio $C(z) / C_{\mathrm{s}}$, where $C(z)$ is the dopant concentration at a depth $x$ inside the film and $C_{\mathrm{s}}$ its surface concentration. The figures $1 a$ et $1 b$ show the iodine profiles for $y=0.008$ and $y=0.15$. We clearly observe a non homogeneous dopant concentration mainly for $y=0.008$ and on the other hand the dissymmetry of the profile; such last effect can be attributed to the non homogeneity of the sample (shiny and dull surfaces). On the figures $2 a$ and $2 b$ 


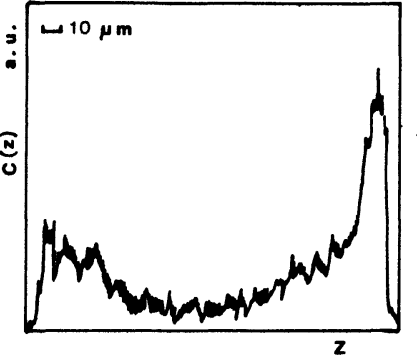

a)

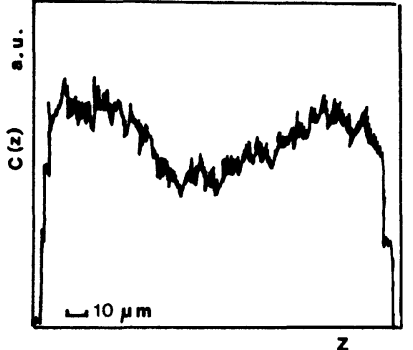

b)
Fig. 1. - Iodine profiles through a polyacetylene film : a) light doped sample $\left[\mathrm{CHI}_{0.008}\right]_{x}, b$ ) heavily doped sample $\left[\mathrm{CHI}_{0.15}\right]_{x}$.

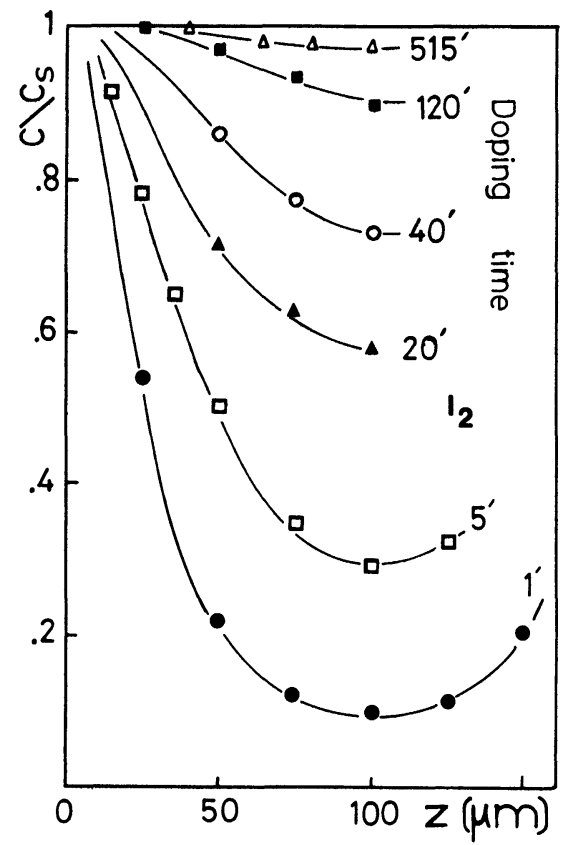

a)

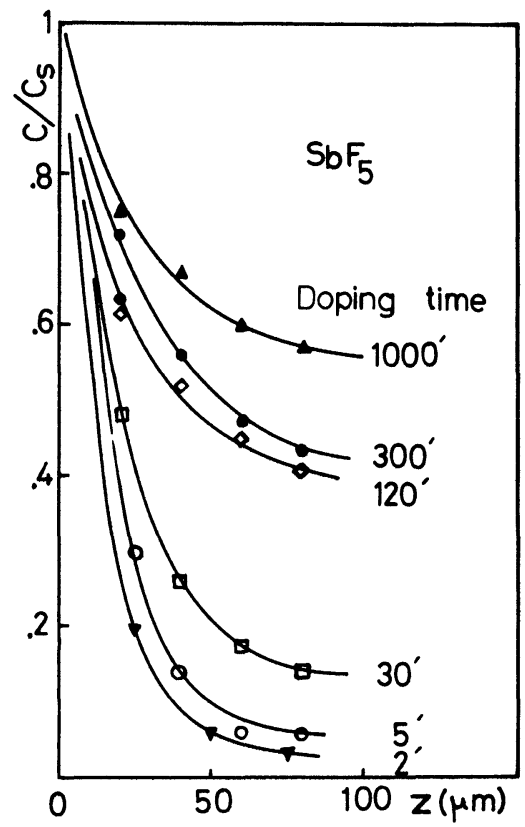

b)

Fig. 2. - Iodine (2a) and antimony (2b) profiles obtained after various doping times with $\mathrm{I}_{2}$ and $\mathrm{SbF}_{5}$. are respectively reported the iodine and antimony profiles obtained after various doping times (vapour phase doping with $\mathrm{I}_{2}$ and $\mathrm{SbF}_{5}$ ). We must notice that $\mathrm{SbF}_{5}$ produces a more inhomogeneous doping effect than $\mathrm{I}_{2}$.

3. Discussion. - Generally the impurity (dopant) concentration through a sample is explained using the usual Fick's law. In our case, the dopant concentration profile $C(z, t)$ is, for a long doping time,

$$
C(z, t) \simeq C_{0}\left[1-\frac{4}{\pi} \sin \left(\frac{\pi z}{l}\right) \exp \left(-\frac{\pi^{2}}{l} D t\right)\right]
$$

and its mean value $\bar{C}$ through the slide was calculated by Bénière et al. [3] and reduces to :

$\bar{C}=\frac{4 C_{0}}{l} \sqrt{\frac{D t}{\pi}}$ for a short doping time

and

$\bar{C} \simeq C_{0}\left[1-\frac{8}{\pi^{2}} \exp \left(-\frac{\pi^{2} D t}{l^{2}}\right)\right]$

for a long doping time

relations in which $C_{0}$ is given by the vapour pressure of the gazeous dopant (its value is fixed by the temperature at which the doping process is performed), $D$ is the dopant diffusion coefficient, $t$ the time and $l$ the slide thickness.

From one of these equations we can deduce the dopant diffusion coefficients, we found $D \simeq 10^{-7} \mathrm{~cm}^{2} \mathrm{~s}^{-1}$ for iodine and $D \simeq 10^{-8} \mathrm{~cm}^{2} \mathrm{~s}^{-1}$ for $\mathrm{SbF}_{5}$. However we must notice same discrepancy between the values obtained from the various curves corresponding to short or long doping time. This will be discussed after. On the other hand, we have reported the relative mean value of dopant concentration through the sample $\bar{C} / C_{\mathrm{s}}$, obtained from the experimental measurements, versus the square root of the time (Fig. 3). For $\mathrm{I}_{2}$ and $\mathrm{SbF}_{5}$ we observe clearly

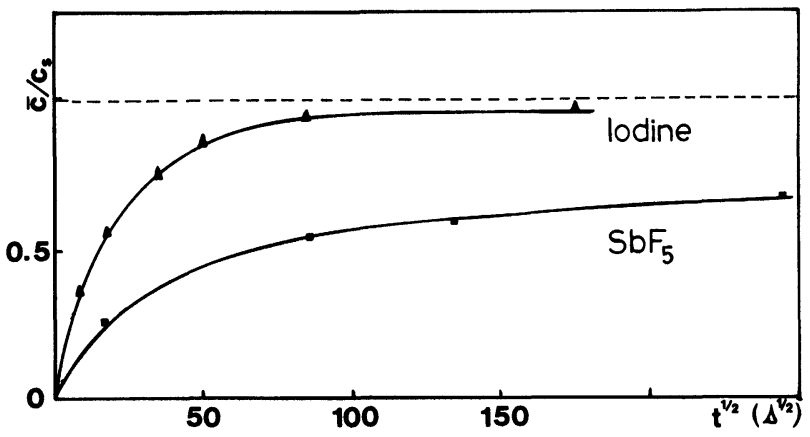

Fig. 3. - Relative mean value of dopant concentration $\bar{C} / C_{s}$ versus the square root of doping time.

a linear dependence at the beginning and a saturation for long doping time in agreement with the relations [2] and [3]. The starting material presents an uniform 
density in its cross section. However we must notice that it is not a compact material and microprobe analysis interpretation must be modified; to this end, a study was performed and published elsewhere [6].

However we think that this simple approach of the dopant " diffusion " in $(\mathrm{CH})_{x}$ film is very crude. From the far infrared experiments Montaner et al. [7] have observed a variation of the complex refraction index, attributed to a dopant gradient through the sample.

On the other hand such a result clearly shows that, even at very low doping levels, the surface dopant concentration is important. Until now, all the measured properties were related to $y$, which is the mean value of the dopant contents. So, many errors could be made about the properties of the doped material. For example, at a given concentration $y$, the electrical conductivity measured by a planar experiment will be enhanced (high dopant concentration case) and by a sandwich measurement it will be reduced (undoped or low doped sample). Identical effect can be observed in optical transmission or reflexion measurement.

In conclusion we can assume that, for the $(\mathrm{CH})_{x}$ films at low dopants contents, it is necessary to verify the dopant profile, and take it into account in the physical results interpretation. It may be also possible to polish the sample surface until the dopant transversal concentration is uniform. At last the observed profiles are not well explained by the Fick's law diffusion and we think that two processes are in competition : dopant diffusion and chemical reaction between the polymer and the dopant who fasten the dopant molecules on the fiber surface and inside them. In order to improve the results obtained from the Fick's law, we have built a model which take into account both the diffusion and a chemical binding process between the dopant and the $(\mathrm{CH})_{x}$ chains or fibrils. Elsewhere we took into account a diffusion coefficient depending on the local dopant concentration. An extensive study of this model [8] allows us to coroborate these experimental results. At last Moses et al. in a recent paper [9] pointed out that the non uniform doping effect on electrical transport in trans- $(\mathrm{CH})_{x}$ must be taken into account in order to determine the critical dopant concentration $y_{\mathrm{c}}$ at which the semiconductor to metal transition occurs. They assumes that the general admitted value $\left(\bar{y}_{\mathrm{c}} \simeq 0.02\right)$ must be modified and really lies near $\bar{y}_{\mathrm{c}} \simeq 0.002$.

\section{References}

[1] Chiang, C. K., Fincher, C. R., Park, Y. W., Heeger, A. J., Shirakawa, M., Louis, E. J., Gau, S. E., Mac Diarmid, A. G., Phys. Rev. Lett. 39 (1977) 1098.

[2] Park, Y. W., Ph. D, Thesis Univ. Pennsylvania, Philadelphia 1980.

[3] Benière, F., Haridoss, S., Louboutin, J. P., Aldissi, M., Fabre, J. M., J. Phys. Chem. Solids 42 (1981) 649.

[4] Ito, T., Shirakawa, M., Ikeda, S., J. Polym. Sci. 12 (1974) II.
[5] Fincher, C. R., Osaki, M., Heeger, A. J., Mac DiarMID, A. G., Phys. Rev. 19 (1979) 4140.

[6] Rolland, M., Cadene, M. et al., Mat. Res. Bul. 16 (1981) 1045 .

[7] Montaner, A., Galtier, M., Benoit, C., Aldissi, M., Phys. Status Solidi (a) 66 (1981) 267.

[8] Benort, C., Rolland, M., Aldissi, M., Rossi, A., Cadene, M., Bernier, P., Phys. Status Solidi (a) 68 (1981) 209.

[9] Moses, D., Denenstein, A., Chen, J., MCAndrew, TWOerner, P., JeEger, A. J., MAC Diarmid, A. G., Park, V. W. (Preprint). 